Última Década, N46, Julio 2017, pp. 71-116

\title{
TRAYECTORIAS E INFLEXIONES EN EL ESPACIO DE OCIO FESTIVO JUVENIL EN LA CIUDAD DE CONCEPCIÓN - CHILE ${ }^{1}$
}

\author{
RODRIGO GANTER SOLÍS ${ }^{2}$ \\ ÁNGELA RIVERA MARTÍNEZ ${ }^{3}$ \\ HÉCTOR Cuevas STEgMAIER ${ }^{4}$
}

Ha salido un nuevo estilo de baile

y yo no lo sabía

y yo no lo sabía

En las discos todos lo practican pero yo no voy a las discos pero yo no voy a las discos

En la calle todos lo comentan pero yo no salgo a la calle pero yo no salgo a la calle

Ha salido un nuevo estilo de baile todos lo bailan pero yo no bailo todos lo bailan pero yo no bailo Emociones Clandestinas, Concepción 1987

${ }^{1}$ Especiales agradecimientos a Benja; por sus agudas apreciaciones y por abrirnos su mundo festivo.

${ }^{2}$ Sociólogo, Doctor en Estudios Urbanos, Universidad Católica de Chile. Investigador responsable Proyecto FONDECYT N ${ }^{\circ}$ 1114086. Investigador Asociado Proyecto Anillo Juventudes SOC 1108; Profesor del Depto. de Sociología, Universidad de Concepción -Chile.rganter@udec.cl.

${ }^{3}$ Socióloga, Universidad de Concepción; Maestría (c) en Antropología Social - ENAH, México. Investigadora Asistente Proyecto Anillo Juventudes SOC 1108. angelariveramartinez@gmail.com

${ }^{4}$ Sociólogo, Universidad de Concepción. Tesista Proyecto Fondecyt № 1114086. hecueste@gmail.com 
72 Trayectorias e inflexiones en el espacio de ocio festivo juvenil en la ciudad de Concepción - Chile

\section{RESUMEN}

Este texto presenta y discute los resultados de investigaciones sobre dinámicas de subjetivación juvenil en el Chile actual ${ }^{5}$. El objetivo se orienta a describir los principales cambios en el ámbito del ocio festivo juvenil y las sociabilidades que se construyen en torno a éste, preferentemente las desplegadas a partir del golpe militar de 1973; concentrando los principales hallazgos en las dinámicas juveniles actuales. Nos interesa ir más allá de los ámbitos convencionales de socialización juvenil como la familia, escuela y el trabajo, para explorar sus interacciones desde el ocio festivo, en tanto espacio de autonomía cultural relativa y donde se hace más perceptible y expresiva la construcción cotidiana del mundo simbólico juvenil, sus aceleraciones, transiciones y tensiones, en tanto metáforas del cambio social. La metodología utilizada es de carácter etnográfico y vivencial, y está centrada en un estudio de caso circunscrito a grupos de jóvenes de segmentos medios en la ciudad de Concepción, durante el año 2014 y parte del 2015. Sostenemos que el ocio festivo no sólo constituye un espacio que se agota en el consumo comercial y la diversión, sino que configura un espacio de mediación, “interrupción”, re-interpretación y gestión del orden parental, escolar y oficial para muchos jóvenes actuales.

PALABRAS CLAVE: JUVENTUDES, OCIO FESTIVO, CONSUMO CULTURAL, DINÁMICAS DE SUBJETIVACIÓN.

\section{TRAJETÓRIAS E INFLEXÕES NO ESPAÇO DE LAZER FESTIVO JUVENIL NA CIDADE DE CONCEPCIÓN - CHILE}

\section{RESUMO}

O seguinte texto apresenta e discute os resultados de pesquisas sobre dinâmicas de subjetivação juvenil no Chile atual. O objetivo está orientado para descrever as principais mudanças no âmbito do lazer festivo juvenil e as sociabilidades construídas ao redor deste, preferentemente as acontecidas a partir do golpe militar de 1973; concentrando as principais descobertas nas dinâmicas juvenis atuais. Para nós é importante ir para lá dos âmbitos convencionais de socialização juvenil como a família, escola e o trabalho, para explorar suas interações desde o lazer festivo, em todo espaço de autonomia cultural relativa e onde é mais perceptível e expressiva a construção

\footnotetext{
${ }^{5}$ Proyecto FONDECYT Nº 1114086 y Proyecto Anillo Juventudes SOC 1108
} 
cotidiana do mundo simbólico juvenil, suas acelerações, transições e tensões e metáforas da mudança social. A metodologia utilizada é de caráter etnográfico e vivencial; e está concentrada em um estudo de caso circunscrito a grupos de jovens de segmentos médios na cidade de Concepción, durante o ano 2014 e parte do ano 2015. Sustemos que o lazer festivo não só constitui um espaço que se esgota no consumo comercial e a diversão, mas também que configura um espaço de mediação, “interrupção”, reinterpretação e gestão da ordem parental; escolar e oficial para muitos jovens atuais.

PALAVRAS-CHAVE: JUVENTUDES - LAZER FESTIVO - CONSUMO CULTURAL -

DINÂMICAS DE SUBJETIVAÇÃO.

\title{
PATHS AND BREAKING POINTS IN THE FESTIVE YOUTH LEISURE SPACE IN THE CITY OF CONCEPCIÓN - CHILE
}

\begin{abstract}
The present text presents and discusses the results of researches on dynamics of youth subjectivation in Chile nowadays, oriented to describe the main changes in the field of youth festive leisure and the sociabilities built around it, with a preference for those developed after the military coup of 1973, especially for main findings on the current youth dynamics. By offering insight beyond the conventional areas of youth socialization such as family, school and work, we are focused on exploring their festive leisure interactions as a space of relative cultural autonomy where the daily construction of the symbolic youth world becomes more perceptible and expressive, as well as its accelerations, transitions and tensions as metaphors of social change. On the basis of an ethnographic and experiential methodology, centered on a case study of groups of middle class youngsters from Concepción during 2014 and part of 2015, we assert that festive leisure is not only a space absorbed by consumption and fun but it also configures a space of mediation, "break", re-interpretation and management of parental, school and official order for many young people today.

KEYWORDS: YOUTH - FESTIVE LEISURE - CULTURAL CONSUMPTION - DYNAMICS OF SUBJECTIVATION.
\end{abstract}


74 Trayectorias e inflexiones en el espacio de ocio festivo juvenil en la ciudad de Concepción - Chile

\section{ENFOQUES EN USO.}

Partimos reconociendo que la juventud es un concepto vacío de contenido fuera de su contexto histórico y socio-cultural (Valenzuela, 2009; Reguillo, 2000). Observamos la condición juvenil actual y nos aproximamos a ciertos signos del ocio festivo juvenil en tanto "culturas subalternas -o en resistencia cultural-, que se configuran particularmente a través de sus múltiples prácticas sociales (...). Estos mundos juveniles entran en disputa en la creación de sentido y de su presencia en los espacios públicos (la calle, la escuela), en los privados (la familia), y esencialmente en todos aquellos en los que se escenifican y llevan a cabo una performatividad de sus adscripciones identitarias juveniles” (Nateras, 2010: 18). De ahí la importancia de acompañar epistémicamente estos procesos a partir de las claves de lectura abiertas por la socialidad juvenil, espacio donde se expresa con mayor vitalidad el estar juntos sin ocupación, y donde el sentido de dicha dinámica no es otro que el estar juntos sin más (Urteaga, 2011).

De ahí también nuestra decisión estratégica de explorar en los intersticios y las zonas opacas de las diversas formas de vida juvenil (Urteaga y Ortega, 2004), particularmente las asociadas con el ocio festivo, especialmente los espacios que generan mayor convocatoria en segmentos medios; en tanto consideramos a este segmento social como aquél que "encarna" más penetrantemente la sociedad en la que vive, sus formas de consumo simbólico, diversión y producción cultural (Wortman, 2003), mediante una dialéctica de refuerzo y re-elaboración creativa de creencias y prácticas hegemónicas (Valenzuela, 2009).

En cuanto al surgimiento de las discotecas, Feixa (1989) señala que dicho dispositivo de entretenimiento surge en Estados Unidos y Europa a finales de los 60, asociado a un auge económico y la consolidación de un mercado juvenil. Pero es en los años 70 donde el fenómeno se potencia con el auge de la música "disco" que disemina su formato en Occidente y 
Latinoamérica. M. Margulis sostiene que "Los cambios en la cultura urbana se expresan, de modo ostensible, en los cambios en las formas de diversión, en el uso del tiempo libre” (1994: 11). Y se pregunta para el caso de Buenos Aires: “¿Por qué la nocturnidad? La ciudad es de los jóvenes mientras los adultos duermen; es otra ciudad (...) Al refugiarse en la noche, se resignifica la ciudad y parece alejarse el poder. Ilusión de independencia apelando al juego del tiempo; tiempo no colonizado en que parece resignar el control (...) Si todos los espacios están colonizados queda el amparo del tiempo como refugio" (1994: 12). Así se van generando espacios de autonomía relativa e inversión del orden hegemónico en contextos de ocio festivo juvenil, culturas de club, antros, etc. Ser joven significa participar de lugares y espacios juveniles, pero eso está mediado por el consumo, por el poder adquisitivo, por el gusto y por las dinámicas de reapropiación juvenil (Thornton, 1996; Feixa, 1998; Martínez, 2003; Pallarés, 2000; Urteaga, 2011; Ramírez, 2012; Benítez, L., González, Y. \& Senn, D. 2016; Nofre, 2009 y 2013).

Para Margulis (1994) la fiesta comercial nocturna tiende a exacerbar los sistemas de dominación y legitimación del mundo adulto y la industria del ocio. En este punto, Leff, Leivi y García (2003) coinciden en la vigencia y la expansión de este modelo vinculado con la industria del estilo para el caso de las fiestas raves en Argentina a comienzos del siglo XXI.

En las investigaciones sobre ocio festivo realizadas en Chile nos encontramos con el trabajo de D. Contreras (1996) donde se explora el espacio festivo a partir de la noción emblemática de "carrete": "El carrete es la fiesta ritual, el encuentro transversal entre personas que poseen biografías fuertemente disímiles que se descubren a sí mismos y a los otros como sujetos. Está asociado a la realidad juvenil y posee una cualidad específica, se concurre a él en búsqueda de sentido, de refuerzo y de identidad.” (Contreras, 1996: 29).

Ch. Matus continúa esta línea al plantear el "carrete" como "parte del guion cultural que ofrece nuestra sociedad a los jóvenes” (2005: 4), un campo 
76 Trayectorias e inflexiones en el espacio de ocio festivo juvenil en la ciudad de Concepción - Chile

para la socialización juvenil y de los códigos a seguir en materia de consumos, sexualidades y adscripciones identitarias, etc. Reconoce a la fiesta como un escenario donde se disputan aspectos sensibles para las nuevas generaciones, "un espacio de construcción ritual de la identidad y es también un negocio, es el punto donde el rito del carrete puede tanto ahogarse en la cultura de masas o llegar a interpelar críticamente a la cultura del logro, a la lógica del trabajo" (Matus, 2005: 24).

\section{ConteXtualización: PRINCIPALES CAMBios E hitos EN LAS PRÁCTICAS DE OCIO FESTIVO JUVENIL EN CHILE.}

\section{EL “MALÓN” COMO ESPACIO DE HIBRIDACIONES FESTIVAS PUERTAS} ADENTRO.

El surgimiento y autonomización de los espacios festivos adscritos a los mundos juveniles, el "carrete", se encuentra íntimamente ligado al Chile de los años 50 y 60. Lo anterior se deriva de las dinámicas modernizadoras -en lo material y lo simbólico- propulsadas por la matriz desarrollista que aceleró las lógicas de urbanización, industrialización, expansión de la matricula educativa, consolidación de una industria cultural segmentada y translocalizada, con un marcado protagonismo de los sectores medios en todas las esferas de la sociedad, y la consecuente visibilización cultural de sujetos juveniles asociados con dichos segmentos sociales (González, 2011).

En ese contexto surge el espacio social y la práctica colectiva del “malón” (Jara, 2003; González, 2011), esto es, reuniones juveniles que se distinguen por ser excluyentes respecto del mundo y los códigos adultos. A diferencia de otros espacios festivos reconocidos en la época, como las "boites", donde destaca el emblemático local santiaguino La Sirena, con show en vivo y dirigido de preferencia a un público más diverso que el juvenil, con mayor poder adquisitivo y con una clara orientación comercial; el "malón" 
constituyó una práctica puertas adentro, es decir, circunscrito espacialmente al ámbito material de la cultura parental (la vivienda), y donde es posible observar dinámicas inéditas de reapropiación de ese espacio por parte de sujetos generacionalmente distintivos. El día sábado y la noche se constituyen en referentes espacio-temporales para la escenificación del “malón”. Una zona de hibridaciones y fronteras que arma distinciones con la cultura parental, pero sin excluirla del todo.

En ese contexto el carácter del consumo y la escenificación del mismo se distinguía por ser exclusivamente juvenil: rock \& roll, la nueva ola chilena, el baile, la producción estética y el estilo, el consumo discreto de cerveza, ron con coca-cola (el cuba-libre), cigarros, etc. Al mismo tiempo, se identifica una dinámica colaborativa y de auto-gestión juvenil del espacio: cada convocado/a hacía su aporte para sostener la fiesta (la casa, las bebidas, los alimentos, los vinilos, etc.); la música obedecía a la selección elaborada por los propios jóvenes. Por último, conformó un espacio de interacción y encuentro entre jóvenes de distinto sexo, abriéndose la posibilidad de intercambio más afectivo y romántico entre pares. El “malón”, en tanto espacio de ocio festivo juvenil, constituyó un hito creativo y de innovación social, preferentemente ligado a grupos juveniles medios y de expresión predominantemente barrial, donde comenzó a cristalizar una dinámica de conformación temprana de identidades juveniles que con posterioridad implicaría una ruptura generacional con los códigos hegemónicos sustentados por el mundo adulto y sus intereses.

\section{Sociabilidades FESTIVAS JUVENILES COMO DISPUTA POR LA DISTINCIÓN SOCIAL PUERTAS AFUERA.}

Con el triunfo de la Unidad Popular en el año 1970, se genera una aceleración de los procesos de nacionalización de los principales recursos del país y una profundización de las trasformaciones sociales enmarcadas en un proyecto político de carácter socialista. Se observa un clima social y político de 
mayor polarización interna como consecuencia de un contexto internacional donde imperaba la guerra fría. En ese escenario, se observó la emergencia y sedimentación de un campo de construcción de lo juvenil expresado en la proliferación de diversos estilos en disputa que daban cuenta de las tensiones ancladas en la estructura social chilena. La llamada generación del 68 abrió nuevas perspectivas de desenvolvimiento juvenil, expresándose a inicios de los 70 una nueva forma de “ser joven” (Jara, 2003). Lo anterior se plasmó en una actitud rebelde expresada en la forma de vestir, el consumo de música, la generación de espacios y circuitos urbanos propios, entre otros marcadores de corte generacional. En esta época, los jóvenes comienzan a salir de la órbita de tutela más directa y definida por la fiesta puertas adentro, e inician su participación de modo más masivo y complejo en espacios públicos de las grandes ciudades, festivales, “peñas” y las primeras discotecas.

A partir de la segunda mitad de los años 60 la discoteca Las Brujas, ubicada en el sector alto de la ciudad de Santiago, se consolida como espaciotiempo de ocio festivo, encuentro y baile para los segmentos juveniles de clase media-alta y alta de la capital. Fundada en el año 1957 como salón de té, los asistentes comenzaron a bailar espontáneamente haciendo funcionar un wurlitzer. Se llegaba en automóvil, se vestía de modo formal y se bebían licores como "primavera” sin alcohol. Luego comienza a concurrirse en grupos y también en parejas que buscaban espacios para vivir -lejos de la mirada adultasu romance ${ }^{6}$.

Dado el éxito de esta fórmula, comienza a expandirse dicha industria y durante el año 1969 se estrenó la discoteca Eve, también ubicada en el sector alto de la capital, donde convergen -la noche de viernes y sábados- segmentos de jóvenes con poder adquisitivo a pasarla bien, bailar, consumir alcohol, tener

\footnotetext{
${ }^{6}$ Consultar: "El último baile de las Brujas"; revista del Sábado, El Mercurio, edición
} del 28/10/2006. 
encuentros amorosos, encontrase con amigos, etc. A estos espacios se llegaba de preferencia en automóvil como un elemento de distinción social ${ }^{7}$.

En Concepción, la bohemia estuvo muy ligada con la agenda cultural del Teatro Universitario (TUC), la Academia de las Bellas Artes y el Coro Polifónico Arturo Medina. Entre los bares más concurridos estaban los del hotel City y el del hotel Cecil. También figura el local Don Quijote en Plaza Independencia ${ }^{8}$. Y un número no menor de festivales de jazz promovidos por el Club de Jazz de la Universidad de Concepción entre mediados de los años 50 y el año 1965, donde destacan lugares como el Teatro de la Universidad de Concepción y el Ombligo, un pequeño local donde se hacían presentaciones y ensayos ${ }^{9}$.

Para la segunda parte de los años 60, destaca uno de los puntos neurálgicos de la ciudad de Santiago donde se obtenía información de la noche santiaguina. Se trata de la galería comercial Drugstore y la heladería Coppelia, ubicada en la comuna de Providencia. Allí los sábados al medio día se reunía una gran cantidad de jóvenes, para escenificar una cierta estética y un determinado modo de producir y distinguir lo juvenil al interior de una red de relaciones sociales más amplias y muchas veces en tensión con otros segmentos juveniles, generacionales o de clase. Para el caso de Concepción, las dinámicas de distinción generacional también comienzan a observarse de modo más nítido en locales como el Astoria, en pleno centro de la ciudad, y los circuitos vinculados con la propia Plaza Independencia y el Parque Ecuador (Pincheira, 2017).

${ }^{7}$ Consultar: "Discotheque Eve: el lugar donde bailan los santiaguinos desde hace cuatro décadas”; Diario La Tercera, edición del 02/11/2013.

${ }^{8}$ Consultar: "Se apagó con el toque de queda la inolvidable bohemia penquista"; Revista Nos, Abril 2012.

${ }^{9}$ Consultar: “Jazz con ritmo penquista”; Mayo 2015. Revista Nos, Mayo 2015. 
Otro espacio festivo juvenil que se consolida por esos años lo constituyen las “peñas”, pues durante este período se va generando un auge de espacios culturales con marcado énfasis popular ligado a la cultura de izquierda. Lo anterior combustionado por el auge de la "Nueva Canción Chilena”, donde figuran cantantes como Víctor Jara y agrupaciones como Quilapayún, IntiIllimani, etc. La "peña” como espacio de sociabilidad festiva surge a mediados de los años 60 y es reconocido por hacer converger el folclore y las tradiciones populares con la cultura ligada a la militancia de izquierda. Una de las más emblemáticas de la época fue la Peña de los Parra, fundada en el año 1965 y ubicada en una casona patrimonial en pleno centro de la ciudad de Santiago. El público era heterogéneo, aunque de preferencia estudiantes universitarios, también obreros urbanos, grupos de clase media más progresista, artistas diversos y vanguardia (Jara, 2003). La “peña” se configura como un espacio intimista y privilegiado para la difusión de la Nueva Canción Chilena, la cultura popular, la conversación, la construcción de vínculos, etc. (Salazar, 2002). Un espacio de distinción para las juventudes que se alineaban con el centro de gravedad impulsado por la Unidad Popular y rechazaban las formas de ocio festivo promovidas por la llamada cultura burguesa. Las presentaciones de los cantantes y las agrupaciones en las “peñas” eran en vivo, se realizaban en torno a un escenario y los asistentes podían bailar y consumir alcohol, donde el vino destacaba por sobre otros consumos.

Por último, en octubre del año 1970, a pocas semanas de haber obtenido un triunfo electoral la Unidad Popular con Salvador Allende a la cabeza, destaca la realización de uno de los hitos de mayor impacto mediático y social que protagonizara la incipiente cultura hippie local. Se trata del festival Piedra Roja, un evento organizado por un grupo de jóvenes de segmentos medios y medios-altos de la sociedad, aficionados al rock progresivo y psicodélico (Pink Floyd, The Doors, Yes) y que, emulando el festival de Woodstock del año 1969, montaron un concierto en un parque ubicado en los límites de la ciudad de Santiago, en el sector alto de los Dominicos. Allí se dieron cita bandas como 
los Jaivas y los Blops, entre otras ${ }^{10}$. Por esos años también se realizó el festival de rock de Quillón en la región del Biobío y el festival Caminos que se Abren, en septiembre de 1972 (Escárate, 1994; Pincheira, 2017). Los agrupamientos juveniles que construyeron estos espacios para visibilizarse, además de promover la música rock en castellano y poseer una estética particular, buscaban distinguirse y diferenciarse como grupo a través de la práctica del amor libre, el consumo de marihuana, el pacifismo como forma de vida, la integración con el arte y la naturaleza, el rechazo al condicionamiento ideológico del polo militante, etc. Estos jóvenes serían poderosamente influidos por el "neo-folklor", generando lenguajes de fusión altamente innovadores, donde converge lo popular, las raíces andinas, el jazz, el estilo docto y las sonoridades típicas del estilo rock (Salazar, 2002).

\section{GolPE, REPLIEGUE Y DESPLIEGUE DE LA SOCIABILIDAD FESTIVA JUVENIL.}

Los procesos de transformación económica, socio-cultural y política ligados al proyecto de la Unidad Popular fueron violentamente interrumpidos por el golpe militar de 1973. El país se ve fuertemente sometido a dinámicas de represión política y social. La junta militar tomó el control total de los poderes del Estado y decreta estado de sitio en todo el territorio nacional. Lo anterior esparció el miedo y el terror en la ciudadanía. Junto con ello vino el apagón cultural y se restringió la vida nocturna hasta la más mínima expresión. Con posterioridad dichas dinámicas se reorganizarían lentamente y de modo clandestino.

La fiesta fue recobrándose paulatinamente al interior de diversas comunidades, pero esta vez adaptada a las nuevas condiciones de disciplinamiento social y político impuesto por la dictadura. Ejemplo

\footnotetext{
${ }^{10}$ Consultar: "Festival de Los Dominicos"; El Mercurio, edición del 13/10/1970
} 
emblemático de ello fueron las fiestas de “toque a toque” (Jara, 2003), esto es, fiestas organizadas en casas particulares, generalmente de vecinos, y cuyo horario coincidía con la medida de toque de queda que implementó la dictadura en el marco de la vigencia del estado de sitio. Esta medida prohibía la circulación y el desplazamiento por la ciudad de cualquier persona no autorizada, iniciándose a las 22:00 hrs. y concluyendo a las 06:00 hrs. De ahí la denominación de fiestas de "toque a toque”, pues se debía permanecer toda la noche al interior del domicilio donde se generaba el encuentro.

Pero es en el año 1978 con la difusión de la Onda Disco y con la suspensión de la medida del toque de queda a partir de abril, que comienza a generarse una reorganización importante en la industria del ocio festivo y las formas de consumo juvenil ligado a dicha industria.

En el año 1979 se inaugura la Disco Hollywood en un barrio de clase media tradicional e ilustrada de la ciudad de Santiago, Ñuñoa. El espacio destaca por su elaborado diseño, con dos túneles de acceso tapizados por muros de ampolletas y luces, un bar de 20 metros de largo, caídas de agua, bolas de espejos, luces de colores, etc. A dicha escenografía, se le sumó una estética juvenil acorde con el imaginario cinematográfico dominante, centrado en la película “Fiebre de sábado por la noche”. Se bailaba en una pista iluminada, con música de los Bee Gees, KC and The Sunshine Band, Gloria Gaynor, etc. ${ }^{11} \mathrm{~A}$ comienzos de los 80 la discoteca Eve $^{12}$ y la discoteca Gente también se sumaron al boom de la Onda Disco, recuperando un perfil de usuarios ente 25 y 35 años, es decir, jóvenes profesionales con mayor poder adquisitivo ${ }^{13}$.

\footnotetext{
${ }^{11}$ Consultar: "Stayin Alive”; La Nación, edición 24/08/2008.

12 Consultar: "Discotheque Eve: el lugar donde bailan los santiaguinos desde hace cuatro décadas”; Diario La Tercera, edición del 02/11/2013.

13 Consultar: "La discoteque más famosa de los 80 reabre sus puertas”, La Tercera, edición 15/07/2012.
} 
En contraste con esta escena festiva donde se construía lo juvenil, destaca la "peña” Javiera, que funcionó desde mediados de los 70 hasta 1980 en la calle San Diego, en pleno centro de Santiago, y que serviría como soporte de encuentro y reconstrucción de redes estudiantiles para la Agrupación Folclórica Universitaria y posteriormente la Agrupación Cultural Universitaria ACU (Muñoz, 2002; Santis, 2009). En interdependencia con estos espacios, surgiría durante el año 1982 y en plena crisis económica, el emblemático local Café del Cerro, ubicado en el barrio Bellavista, en el corazón de la ciudad de Santiago. Allí, en contexto de censura, se difundió la poesía, el teatro y especialmente el “Canto Nuevo”, considerado -este último- como parte de un movimiento cultural juvenil de preferencia universitario, que usó por primera vez dicha expresión musical como herramienta de protesta contra la dictadura y compromiso social. Allí tocaron bandas como Congreso, Santiago del Nuevo Extremo, los Prisioneros, etc. ${ }^{14}$ Para algunos medios y diversos actores juveniles, estos grupos de jóvenes estudiantes universitarios se adscribían dentro del estilo “Lana” o “Artesa” (artesanal), fundamentalmente por como vestían, la música que escuchaban, los lugares que frecuentaban y su compromiso en la lucha contra la dictadura.

En esos años, en la ciudad de Concepción, destacan lugares de refugio y encuentro estudiantil y juvenil, como la Parroquia Universitaria, donde se le dio forma y vida a la Agrupación Cultural Concepción (ACC), fundada el año 1978. Asimismo, figuran otros espacios culturales para el reagrupamiento y el encuentro como la Sociedad de Carpinteros y Ebanistas; el sindicato de trabajadores de Gacel, ubicado en calle Los Carrera; y la denominada Aula Cero (donde la Tía Títa), concurrida cervecería frecuentada por estudiantes de la Universidad de Concepción, ubicada en la Población Agüita de la Perdiz en el entorno del Barrio Universitario (Sagredo, 2013).

\footnotetext{
${ }^{14}$ Consultar: “Santiago Underground”, La Nación, edición 31/12/2006.
} 
84 Trayectorias e inflexiones en el espacio de ocio festivo juvenil en la ciudad de Concepción - Chile

En un polo más disruptivo, durante los años 1983 y 1984, junto con la irrupción de las protestas callejeras masivas, van surgiendo expresiones más “under” y contraculturales en la noche santiaguina, que se proyectaron hasta finales de los años 80. Destaca el surgimiento de espacios de resistencia cultural como lo fue el Trolley en la calle San Martín, un viejo edificio que había funcionado como sindicato. En esos años comenzó a funcionar como centro cultural clandestino donde se podían ver obras de teatro, poesía, danza, cine, etc. Y el Garaje Matucana, en pleno barrio Estación Central (Fernández, 2011), donde se organizaron encuentros, fiestas, performance, tocatas en las que se presentaron bandas chilenas de rock alternativo como los Electrodomésticos y de estilo punk como: Pinochet Boys, Fiskales Ad-Hok, Politikos Muertos, etc. $^{15}$, conformando una escena urbana subterránea y de hibridaciones alternativas, donde el look predominante era de negro y las pertenencias fueron de carácter intergeneracional. En este espacio anti-dictadura se consumía todo tipo de alcoholes y marihuana, y de preferencia convocaba a jóvenes de diversa procedencia social: estudiantes universitarios; grupos de intelectuales de lo marginal y un grupo heterogéneo de artistas que comenzaba a problematizar las relaciones entre arte, política y memoria. En un clima de mayor apertura por parte de la dictadura, memorables fueron las fiestas del "montón de inscritos" para la coyuntura del plebiscito de 1988, en cuyo resultado la ciudadanía terminaría rechazando mayoritariamente la perpetuación del dictador Pinochet en la presidencia del gobierno. Hito con el cual se iniciaría la década de los 90.

Para la primera parte de los 80 en Concepción destacan como hitos aglutinantes y de reconocimiento juvenil, los espacios radiales juveniles vinculados a la Radio de la Universidad de Concepción, como el programa La Ampolleta Encendida, con énfasis en la difusión de la música anglo, new wave; y en el año 1984 el concierto en el aula magna de la Universidad Católica de

${ }^{15}$ Consultar: “Santiago Underground”, La Nación, edición 31/12/2006 
Concepción, donde tocó la banda los Prisioneros de Santiago y los Ilegales de Concepción ${ }^{16}$.

\section{RETORNO A LA INSTITUCIONALIDAD DEMOCRÁTICA (“EN LA MEDIDA DE LO POSIBLE”).}

Para 1989 el país tendría al primer presidente electo democráticamente luego de 17 años de dictadura militar. Para ese momento se observa nuevamente la colonización de la calle, la ciudad y la noche en las principales ciudades del país. Se escucha, baila y difunde masivamente a la banda los Prisioneros, "la voz de los ochenta"; se trata de una nueva fuerza generacional que rompió la inercia cultural de esos años, y con ello sobrevino una explosión de nuevas bandas de rock chileno (Escárate, 1994).

En ese marco, 1991, van surgiendo las llamadas fiestas Spandex (Fernández, 2011), un tipo de fiestas alternativas, eventos diseñados y montados por colectivos de actores vinculados a la escena de vanguardia (entre ellos el memorable actor Andrés Pérez), diseñadores, gente de la televisión, hijos de retornados políticos, etc. El lugar: el antiguo teatro Esmeralda, ubicado en el centro de Santiago, donde se elaboraba una escenografía especial para desfiles, performance, etc. De fondo se mezcla la música de estilo House con New Wave y Punk. No llegaban hippies, “lanas” o “artesas”. Era básicamente lo que se llamó el "red-set". Los eventos llegaron a convocar más de 600 asistentes, entre ellos: jóvenes y artistas de diversa procedencia, muchos lo consideraron un territorio de intercambio interclasista (Palma, 2013).

Surgen los circuitos de ocio y espacios festivos juveniles. El reconocido barrio Bellavista en la ciudad de Santiago adquiere protagonismo, ya que se posiciona como un lugar concurrido masivamente por los jóvenes,

\footnotetext{
${ }^{16}$ Consultar:“La historia de Jorge González y su indisoluble vínculo con Concepción”;
} Diario Concepción; 22/11/2015 

ciudad de Concepción - Chile

convirtiéndose en un espacio de recreación y expresión durante la dictadura y la pos dictadura, y donde se mezcló la acción cultural con la política. Entre los circuitos de alta convocatoria también estuvo la Batuta en el sector de Plaza Ñuñoa y la discoteca Blondie, que articuló un circuito barrial más cercano al "under”, situado principalmente en los barrios céntricos de Santiago, como Brasil y Yungay (Matus, 2000). Surge un ambiente urbano de destape, expresión y desinhibición cultural.

En el caso de la Blondie, ésta comienza a funcionar en el año 1993 justo donde antes funcionaba un cine xxx. De algún modo este espacio recibía toda la fauna humana que quedó a la deriva luego de que las fiestas Spandex desaparecieran. Los viernes comienzan a editarse lo que se llamó fiestas alternativas, al cual llegan grupos que re-editan el punk y new wave. También asiste un púbico más heterogéneo, de preferencia estudiantes universitarios ligados a carreras de arte. Asimismo, a pesar de que la Blondie no estaba orientada predominantemente hacia público gay, llegan grupos de jóvenes adscritos a dicha orientación sexual. Al interior de la disco opera una diferenciación según el estilo, donde la legitimidad se vincula con la trayectoria de cada individuo en el espacio social. Al final el local privilegiará lo alternativo por sobre lo masivo, aunque posteriormente eso se pondría en disputa en los años siguientes (Matus, 2000 y 2005; Fernández, 2011).

Este fenómeno también comenzó a expresarse durante los 90 en Concepción, donde se consolida el Barrio Estación como un circuito de carrete juvenil con una variada oferta de ocio festivo nocturno. Muchos de estos espacios ensayaron propuestas alternativas a lo puramente comercial. En ese contexto irrumpe a mediados de los 90 el emblemático bar Cariño Malo, donde de preferencia se cultivaron estilos como el rock, el jazz y el blus en vivo (iniciativa impulsada por el actual dueño del Casa de Salud). Además incluía una galería de arte. Luego aparecieron locales de música como el Bar La 
República, con un estilo tecno, house. Y el Bar del Frente, con música más mestiza, étnica y de fusión ${ }^{17}$.

Con el avance de la normalización democrática, el carácter cultural y político que había mostrado la fiesta a finales de los 80 se modifica, adquiriendo nuevas manifestaciones y lógicas de gestión. El concepto de pub (del public house británico), colonizará rápidamente el paisaje festivo juvenil. El pub respondió a una reorganización del ocio nocturno masivo en un contexto de transición política y cultural. Estaría definido por un local comercial más compacto, diseñado para beber, comer, escuchar música, bailar y compartir entre iguales; de preferencia orientado a un público con poder adquisitivo.

El barrio Bellavista en Santiago se reconvierte de un espacio ligado a la cultura de contestación frente a la dictadura, a un barrio orientado a la "cultura festiva” en sí misma, cuyo público objetivo se diversifica como parte de una colonización más comercial, donde la diversión se va industrializando mediante códigos de carácter masivos y globales en un contexto de expansión económica nacional. Fenómeno que también se pudo observar más nítidamente en la experiencia y trayectoria que conformó el circuito festivo ligado al barrio Suecia, en el sector de alta renta en Santiago durante los 90.

Asociado con lo anterior, por esta época se va consolidando un sentimiento generalizado en los jóvenes de desafección con la forma de hacer política que dominó el momento de la transición: el consenso, la transacción, y la política “en la medida de lo posible”. Se releva entonces el rol del grupo de pares, la participación en ámbitos de la vida cotidiana, las relaciones cara a cara y los modos de organización informales, no sujetos a estructuración jerárquica. El reconocimiento juvenil adquiere gran importancia, particularmente el “carrete”, donde se observa una reagrupación juvenil por abajo, en los bordes del sistema normativo y convencional. Las juventudes se dispersan

\footnotetext{
${ }^{17}$ Datos registrados en el marco de entrevista etnográfica realizada a Dj Negro Pésimo, actual dueño del local Casa de Salud., durante el segundo semestre del año 2015.
} 
horizontalmente cubriendo el territorio con redes, colectivos, bandas musicales, "tribus urbanas" (Ganter y Zarzuri, 1999), barras bravas y otras expresiones. Esto sucede porque los jóvenes necesitaban re-crear socio-emocionalmente un nosotros, donde la cultura de la fiesta y el carrete constituyó una forma de reagrupamiento juvenil y de sociabilidad entre pares, abierta, interclasista y que cumplió funciones de ajuste intersubjetivo para reconstruir espacios, confianzas y afectos colectivos (Contreras, 1996; Ganter y Zarzuri, 1999; Matus, 2001; Salazar, 2002).

\section{POSFIESTA: NEO-DIVERSIDAD Y SEGMENTACIÓN SOCIO-ESPACIAL.}

En el actual panorama urbano santiaguino se pueden distinguir sectores y zonas tradicionales de "carrete" vinculado a locales y barrios emblemáticos de fiesta y diversión, o bien, circuitos emergentes con una nueva oferta de ocio y “carrete”. En general, se observa un nuevo tipo de diversidad, fuertemente jerarquizada por la segmentación del espacio y el nivel socio-económico. Así nos destacamos para el caso de Santiago 2 macro-zonas: (1) el llamado cono de alta renta, donde están ubicadas las comunas con mejor índice de desarrollo humano y que concentra a las familias de altos ingresos; y (2) el llamado centro del Gran Santiago, más histórico y con mayor heterogeneidad social y cultural, aunque expuesto hoy a importantes procesos de renovación urbana, lo que ha generado dinámicas de gentrificación y la llegada de nuevos tipos de residentes asociados con nuevos estilos de vida y dinámicas consumo.

Para el caso de la primera macro-zona, ésta se encuentra orientada a un público adulto-joven y perteneciente a la elite social, donde se construye un polo de divertimento escasamente permeado por otras clases y segmentos sociales. Aquí se distinguen las siguientes comunas y circuitos de ocio: 
a) Comuna de Vitacura - circuito Borde Río; b) Comuna de las Condes circuito Apoquindo; c) Comuna de Providencia - circuito Orrego Luco y Manuel Montt; d) Comuna de Ñuñoa - circuito Plaza Ñuñoa.

Para el caso de la segunda macro-zona, más permeable a la diversidad social y en diálogo con gustos heterogéneos, destaca el centro del Gran Santiago, con una oferta dirigida preferentemente a estudiantes universitarios, jóvenes profesionales y un segmento de la nueva clase media con mayor capital cultural. Muchos de éstos conforman los nuevos residentes que llegaron al sector a partir de la renovación urbana iniciada a comienzos del año 2000:

a) Barrio Bellavista - circuito Patio Bellavista; b) Barrio Lastarria circuito Mulato Gil; c) Santiago Centro - circuito centro; d) Barrio Brasil.

La fiesta y su efecto de recomposición socio-emocional por abajo, su militancia cultural y su desenfado con la llamada "democracia cartucha” que predominó durante los años 90, hoy se observa ampliamente desdibujada, sus circuitos reconvertidos, los barrios de mayor carácter e identidad festiva son permeados por los procesos de gentrificación urbana, remodelando sus lenguajes, ofertas y consumos (Wortman, 2003; Melcer, 2003). La mayoría abiertos a gustos y estéticas globales, para el goce sofisticado y personalizado de quienes pueden pagar. En ese marco, se observa una nutrida diversidad de usos y ofertas para públicos juveniles muy variados, que ficcionan y simulan un ambiente cosmopolitano y alternativo, pero disociado, debido a su complejo sistema de segmentaciones sociales y jerarquizaciones espaciales. Es la privatización del ocio festivo, la posfiesta como tendencia predominante en las grandes ciudades. 


\section{CONCEPCIÓN: CAMBIOS URBANOS Y NUEVAS DINÁMICAS DE OCIO FESTIVO JUVENIL.}

La ciudad de Concepción se ubica a $500 \mathrm{~km}$ al sur de la ciudad de Santiago, y es la segunda ciudad más importante del país. Actualmente Concepción se define por ser una ciudad universitaria. Desde los años 90, su área metropolitana vive un proceso de fuerte expansión e incluye una población cercana al millón de habitantes. Este hecho se puede observar con el surgimiento de nuevos condominios para una nueva clase media periurbana y también en la fuerte presencia de equipamiento comercial conurbano, lo que ha llevado a un deterioro parcial del centro de la ciudad y de los barrios tradicionales, derivado de la inflación de la inversión inmobiliaria privada, particularmente después del terremoto del año 2010. Junto con ello se observa un importante desmantelamiento del proceso de industrialización inaugurado a mediados del siglo XIX y que comienza a hacer crisis a contar de la década de los 90. Consecuentemente con esto se observa una orientación hacia la economía de servicios, donde también destaca una trasformación importante en la estructura de clase y la emergencia de una heterogénea y fragmentaria clase media, donde se visualiza una estructura ocupacional diferente a la tradicional, definida por profesiones y empleos de nuevo tipo, muchas veces altamente flexibilizados y precarizados.

En ese marco, destacamos al menos tres barrios asociados fuertemente con el ocio festivo: Barrio Estación, Barrio Universitario y Barrio Argentina y/o Brasil

Se evidencia un tránsito del ocio festivo en la ciudad, desde el centro (Barrio Estación - Barrio Universitario) a los bordes del centro, marcado por el terremoto del año 2010, momento en el que surge el circuito ligado al denominado Barrio Argentina y/o Brasil. Barrio histórico de la ciudad y asociado con un fuerte componente industrial de principios del siglo XX. Socialmente heterogéneo, donde coexiste una estructura social que combina los 
segmentos obreros con una clase media tradicional. Morfológicamente, coexisten diversas tipologías de viviendas con infraestructuras y galpones de tipo industriales, muchos de ellos hoy reutilizados para locales de ocio nocturno.

Para el sector del Barrio Estación, analizaremos el caso de las Party Hard. Fiestas generadas al interior del local Living Room. Este Barrio constituye una zona característica de la ciudad, donde se encontraba la antigua estación de ferrocarriles y la vida bohemia que data mediados del siglo XX. Actualmente destaca por concentrar actividades ligadas con la administración pública y de tipo comercial. Durante la noche funciona como núcleo de actividades para el ocio festivo juvenil y el carrete.

Para el Barrio Argentina y/o Brasil, analizaremos el caso de "Casa de Salud”, pues cuenta con una serie de elementos que lo transforman en un lugar muy interesante para estudiar la fiesta juvenil. Su forma de vivir y experienciar la fiesta de modo horizontal; la coexistencia de diferentes juventudes y facciones ligadas a los grupos medios de la ciudad; la propuesta de una serie de ambientes que mezclan el arte, la música, la cultura y lo festivo; un concepto y diseño de ambientes altamente elaborado; y cierto clima social y cultural que remite a la metáfora de un caleidoscopio urbano-juvenil.

\section{ESTRATEGIA METODOLÓGICA.}

El trabajo se plantea desde un enfoque metodológico etnográfico (Guber, 2001). En este contexto, privilegiamos lo que se entiende por etnografía de eventos (Borges, en Bonvillani, 2013), donde observamos y participamos de un conjunto de fiestas-eventos convocados por dos espacios de ocio festivo juvenil definidos como estratégicos en Concepción. Lo anterior derivado de su alta demanda y reconocimiento social en la ciudad. Los casos 
seleccionados son: el Party Hard y Casa de Salud, ambos orientados a jóvenes, de preferencia pertenecientes segmentos medios de la ciudad.

El primer caso está asociado a un barrio de bohemia y diversión tradicional de la ciudad (barrio Estación), donde los usuarios que observamos se reconocen generacionalmente por ser jóvenes de segmentos medios y mediobajo, la mayoría pertenecientes a la educación secundaria, y de diversa procedencia territorial y barrial en el contexto del Gran Concepción.

El segundo caso está asociado a un barrio de ocio festivo emergente en la ciudad (Barrio Argentina), donde la mayoría de los usuarios se reconocen generacionalmente por ser jóvenes de segmentos medios y medio-alto, de preferencia estudiantes universitarios, gente del mundo de las artes y jóvenes profesionales.

Para acercarnos al campo decidimos realizar en una primera fase, sucesivas incursiones por medio de la observación participante y la posterior construcción de relatos etnográficos. En una segunda fase, combinamos las técnicas de observación con instancias de producción discursiva a través de entrevistas y grupos focales con jóvenes usuarios de estas fiestas y también con jóvenes que trabajan asociados con la instancia que organiza el espacio festivo.

Las incursiones de campo se dieron entre marzo del año 2014 y julio del año 2015. Para zanjar el posicionamiento estratégico en el campo definimos nuestro "rol maestro" en tanto usuaria/o de dichos espacios festivos ${ }^{18}$.

${ }^{18}$ En cuanto a las consideraciones éticas, se optó por proteger la identidad de los jóvenes participantes e incluir un tipo de observación sigilosa, es decir, lo menos intrusiva posible para evitar distorsionar las interacciones espontáneas y propias de la conformación de dicho escenario. En relación a los protocolos de consentimiento informado nos apoyamos en lo que propone la American Anthropological Association, pues dada la naturaleza de este proceso no se requiere en todos los casos de un formulario específico escrito o firmado: "Es la calidad del consentimiento, y no su formato, lo que resulta relevante" (AAA, 1998: 3). 
Tabla 1

Participación en eventos Party Hard

\begin{tabular}{|l|l|}
\hline Fecha - participación & \multicolumn{1}{|c|}{ Evento - Party Hard } \\
\hline 12 de abril 2014 & Living Room \\
\hline 19 de abril 2014 & Living Room \\
\hline 31 de mayo 2014 & Living Room \\
\hline 14 de junio 2014 & Living Room \\
\hline 9 de agosto 2014 & Living Room \\
\hline 16 de agosto 2014 & Living Room \\
\hline 06 de junio 2015 & Club Space \\
\hline 11 de julio 2015 & Living Room \\
\hline 24 de julio 2015 & Living Room \\
\hline
\end{tabular}

Tabla 2

Participación en eventos Casa de Salud

\begin{tabular}{|l|l|}
\hline Fecha - participación & Evento - Casa de Salud \\
\hline 17 de abril 2014 & Presentación DJ Imaabs, Tfried y negro pésimo \\
\hline 24 de abril 2014 & Presentación banda Bosque y DJ del local \\
\hline 1 de mayo 2014 & Presentación Banda "Fuma y Baila" \\
\hline 9 de mayo 2014 & Presentación "La canarito" \\
\hline 23 de mayo 2014 & La romería de la santa fortuna \\
\hline 30 de mayo 2014 & Mista Coco e inauguración Mural \\
\hline 5 de junio 2014 & Colina verde y Fiesta "Cetácea" \\
\hline 18 de octubre 2014 & Cumbre "Fenómeno para anormales" \\
\hline 17 de enero 2015 & Proyecto "ermitaño" \\
\hline 25 marzo 2015 & - \\
\hline 14 mayo 2015 & - \\
\hline
\end{tabular}


94 Trayectorias e inflexiones en el espacio de ocio festivo juvenil en la ciudad de Concepción - Chile

\section{Presentación de Resultados}

\section{LAS PARTY HARD.}

Las Party Hard son fiestas que no funcionan como tradicionalmente funciona un espacio-tiempo nocturno de esta naturaleza, sino que operan por las tardes, es decir, de 17:00 hrs. a 22:00 hrs. según informan y avisan los flayer que los organizadores van subiendo a los eventos de Facebook. Las fiestas tienen lugar en galpones, casonas y edificios localizados en barrios antiguos de la ciudad, algo degradados por el paso del tiempo, y que en general se ubican en zonas céntricas de la ciudad de Concepción. En el Barrio Estación, destaca el local Living Room, uno de los más reconocidos por los jóvenes usuarios y usuarias de estas fiestas. Las Party Hard tienen un staff compuesto por jóvenes cuyas edades fluctúan entre 15 y 19 años (5 varones - 5 mujeres), que tienen como actividad básica el trabajar para la producción vendiendo las preventas para la fiesta.

Según su página en Facebook la primera Party Hard data de Noviembre del 2012 y muchos de los primeros eventos combinaban el formato de la fiesta bailable con la tocata. El set-list (música que ponen los $D J$ ) no ha variado demasiado, se conserva y se mezcla el estilo dubstep, noise, electro-pop, hardstyle, rave, electro-house, entre otros. Los estilos de las bandas de las tocatas también se conservan, son principalmente de estilo metalcore, punk rock, post hardcore, deathcore y otros.

Una de las cualidades distintivas de estos espacios festivos, en relación a otros eventos festivos ocasionales, es que son generados por jóvenes y para jóvenes. Esto implica que haya escasa participación de adultos en estos escenarios. Los jóvenes que emprenden este tipo de iniciativas y que han venido renovando el ocio festivo en la ciudad, tienen solo algunos años más que la mayoría de los jóvenes que son usuarios de estas fiestas. Lo mismo se puede observar en los DJ, en los miembros de las bandas de música que se presentan en vivo y el propio staff de apoyo para las preventas. 
Los y las jóvenes que asisten a estos eventos, se caracterizan por provenir de distintos colegios y liceos, tanto en lo referido a sectores y barrios del Gran Concepción, como al tipo de establecimiento, esto es, colegios privados, colegios particulares subvencionados y colegios municipales o públicos. Poseen intereses, prácticas, preferencias, consumos y estéticas globales, pero que confluyen en este espacio de múltiples y complejas interacciones sociales e intercambios culturales, donde se conjuga el gusto por la música, el baile, el consumo de sustancias como el alcohol ${ }^{19}$, el conocer gente, la exploración del deseo y los afectos corporales.

Dentro del espacio las restricciones son muy escasas. Por el contrario hay más permisos que restricciones. Una de las principales prohibiciones que se relaja la constituye la prohibición de venta de alcohol. También se disponen y organizan espacios como terrazas para el consumo de cigarrillos y eventualmente de cannabis.

\section{EXTRAMUROS: LA “PREVIA" Y LA ADUANA.}

Es sábado, faltan pocos minutos para las 17:00 hrs. Pocas cuadras antes de llegar al local es posible identificar algunos chicos y chicas que se dirigen hacia el evento. Llego y me siento en Plaza España, ubicada a pocos metros del lugar. Las chicas y los chicos están dando vueltas por ahí, tomándose fotografías con sus aparatos celulares. Son grupos de 6 a 8 jóvenes. Otros hacen la "previa" con algunas botellas de vodka que mezclan con bebidas gaseosas en botellas plásticas para beber agua. Otros beben cerveza en lata. Al costado del local se observa una fila de jóvenes que se aprestan para entrar a la fiesta. Desde diferentes lados se observan grupos de jóvenes que convergen hacia el

${ }^{19}$ Destacando el consumo de los populares Jelly Shot, bebida en base a gelatina combinada preferentemente con vodka o ron. Otras veces destaca el consumo de golosinas a base de gelatina y de colores llamativos. 
local. Hay aproximadamente entre 50 y 80 jóvenes que están afuera, mientras otros tantos ya se encuentran dentro del local o a punto de entrar.

Me acerco a la fila y escucho atenta. Las conversaciones que se sostienen son referidas principalmente a personas y conocidos que vendrán a la fiesta, y otros tantos que no pudieron venir. A pocos metros del acceso ya se siente la música sonar. Es como un gran pulso cardiaco que se siente bombear desde dentro del local. Paso el primer acceso donde hay control de 2 guardias jóvenes. Ellos están ahí para filtrar y seleccionar únicamente por la pinta, el look de la gente, es la aduana. A algunos jóvenes se les indica que no pueden acceder, ya sea porque vienen muy bebidos o porque su aspecto y/o actitud no es "apropiado". De todas formas, son excepciones, en general se permite y promueve el acceso masivamente. Subo a un segundo piso, la música está a todo volumen. Segundo control: una mujer instalada en una especie de cubículo vende entradas y recibe la preventa. Tercer control: un guardia joven y más corpulento que el resto corta las entradas y marca con un timbre la muñeca de cada uno de los chicos y chicas. Ya estoy adentro. La música y su atmósfera me envuelven, me sumerjo bajo el oleaje.

Ciertamente "pasa" de todo dentro del local, pero también "ingresa" de todo al local. Es decir, participa una variedad importante de "especímenes" como nos dicen; aun cuando las primeras incursiones y conversaciones con el mundo de las Party nos permiten detectar -preliminarmente- al menos tres formas laxas de estéticas que se distinguen en el propio espacio social de la discoteca. Aunque sin consumos, usos o apropiaciones específicas que lleven a disputas por el espacio. Un estilo organizado en torno a lo flaite, un estilo organizado en torno a lo swag; y un estilo organizado en torno a lo zorrón; estos estilos conviven, interactúan y coexisten festivamente en el espacio de la discoteca. La mayoría de composición masculina, aunque insistimos en la permeabilidad y dispersión espacial de estas adscripciones estéticas y 
grupalidades, más pauteadas por moda convencional que por la recombinación de signos, la autoconciencia de grupo y la construcción de una narrativa interna.

\section{INTRAMUROS: PRÁCTICAS, AMBIENTES Y AFECTOS FESTIVOS.}

Recorro el lugar intentando construirme un mapa mental, pero de inmediato me doy cuenta que es una tarea compleja dada la configuración laberíntica del espacio. Sensación acentuada por un enjambre de cuerpos que con-fluyen hacia mí y se con-funden con los sonidos, los espacios, las luces, las pantallas, el murmullo incesante, no se puede conversar sostenidamente. Percibo luces de colores, efectos especiales, la barra y toda la euforia que genera el instante. La barra es pragmática, no exhibe signos importantes, por lo cual no constituye un espacio de distinción y apropiación por grupos de usuarios. De a poco comienza a diluirse la ciudad, la tarde, la noche y las adscripciones más convencionales. Trato de identificar salidas de emergencia, pero no existen.

Los momentos durante la fiesta son una vorágine de sensaciones e imágenes que transitan por este lugar, las emociones se van pegando al cuerpo como el calor que humedece la ropa. Luego de un rato identifico 3 ambientes: cada uno con una plataforma donde están los DJ. Aparecen dos o tres pistas de baile, cada una con sus respectivos set-list. Observo las terrazas para fumadores, aquí se puede conversar.

Los baños; los sectores para sentarse; y más allá lo que llaman: el cuarto oscuro. Un espacio sin iluminación alguna, el cual puede ser utilizado para cualquier fin, pero pensado preferentemente para encuentros más íntimos y afectivos de todo tipo. Únicamente es posible identificar un tipo de iluminación y atmósfera que hace resplandecer los tonos blancos asociados al cuerpo, es decir, la ropa, los dientes, entre otros. A ratos parece desvanecerse la identidad, 
la procedencia, lo real, la estabilidad de los conceptos con los cuales nos explicamos el mundo. Escapo de la participación, retorno a la observación.

Los chicos y las chicas tienen apariencias y estéticas diversas, que toman elementos clásicos del punk, como los estampados de textura animal en las chicas, los jockeys de viseras planas en los chicos, pantalones ajustados, zapatillas clásicas de skate, vans y converse. También se observan proliferar distintos tipos de modificación corporal, sobre todo piercing, algunas expansiones en el lóbulo de la oreja. Todo reorganizado por un estilo generacional particular donde predomina una estética de lo híbrido que reinterpreta elementos de estilos juveniles más clásicos, y re-escribe promiscuamente otros tantos signos nuevos del mercado.

La atmósfera de las fiestas es variable, el tránsito por los distintos ambientes permite captar diferentes temperaturas, pulsos, velocidades y sentidos otorgados a cada subdivisión del local. La movilidad de los cuerpos y el devenir erótico es un aspecto muy presente en cada una de las fiestas, aquello queda de manifiesto en que una gran cantidad de fotografías del registro oficial retrata los encuentros "amorosos" entre usuarios diversos. Aquellas sexualidades móviles y de afectos libres, en varios casos se encuentran fuera de la hetero-norma sexual, lo cual parece no tener una connotación peyorativa para las y los chicos que asisten, es parte de la escena. Muchos chicos y chicas llegan a estas fiestas para puro pelarse, o sea, para mantener múltiples y simultáneos encuentros eróticos y afectivos dentro de la misma fiesta. Muchos de estos encuentros y afectos abiertos al universo de la "hetero-curiosidad" juvenil.

Participando nuevamente, las fricciones y los roces se me hacen inevitables en este enjambre de cuerpos y sensaciones. El calor es inaguantable, se resuelve saliendo un rato a la terraza o bebiendo líquidos con mucho hielo. Todos y todas danzan con todos/as, todos/as danzan con el todo. Todos y todas sudamos mientras llueve la espuma artificial que cae de no sé dónde, pero que 
aumenta la sensación de humedad corporal y ambiental, intensificando la atmósfera de sauna, un ambiente profundamente líquido y orgiástico para todos los chicos y chicas. Acaso una fusión festiva e intensiva de afectaciones corporales y emocionales. Amistad, libertad, promiscuidad, comunidad, euforia. El volumen de la música es fuertísimo -suena MGMT-, todo parece acentuar una des-temporalización y desconexión de todos los exteriores. Se desdibuja el afuera, sólo parece quedar un adentro muy intensivo y personal.

\section{ENTRE EL “BORRARSE” Y EL EXHIBIRSE.}

Las motivaciones para asistir a estos espacios de ocio festivo que aquí describimos, son variadas. Principalmente escuchamos y observamos las de ir a "pelarse", con chicos y chicas.

A partir de las incursiones preliminares del equipo de investigación, se observa como recurrente y transversal la pulsión de parte de los jóvenes por ir a borrase, desaparecer, apagarse, poner en suspenso los condicionamientos sociales y de la propia capacidad de discernir.

Nos dicen: "perder el conocimiento". Eso se valida entre los pares. "El que más toma y el que queda borrado es el mejor (...) es al que lo aplauden más” (grupo focal mixto jóvenes usuarios). "El objetivo de ir a una party hard es hacerse mierda y pelarse, hay casos en que te puedes pelar a muchas...” (Grupo focal staff).

Efectivamente constituye un escape, una huida, de muchos mecanismos de anclaje y normalización social. Por lo que observamos y escuchamos, el borrase responde más a una dinámica de experimentación, a veces autodestructiva, pero que eventualmente se gestiona con la cooperación in situ de los pares. El borrarse lleva implícito también un gesto de distinción, que permite re-estratificarse entre pares: "Cuando te borrai no podi estar consciente 
100 Trayectorias e inflexiones en el espacio de ocio festivo juvenil en la ciudad de Concepción - Chile

de lo que pasa, perdi la noción del tiempo, te vai en la fome, quedai apagao, quedai tirao. Pero el que se hace mierda gana prestigio, una historia que contar” (entrevista staff).

Él o la que queda borrado es inmediatamente asistido por su grupo de amigos, se le pone de pie cuando se ha caído, se lo traslada a una zona donde pueda tomar aire. El borrarse es una práctica colectiva y social, se aprehende y se escenifica en grupo. Se asocia con jugar con los límites del propio cuerpo, del aguante físico y mental, pero teniendo la cobertura del grupo de pares para lograr estabilizarse de modo seguro y protegido.

"En general te borrai en grupo, porque los demás te apañan. Borrarse es jugar con el límite y cuando te borrai los amigos te apañan y te van a dejar a la terraza, te sientan, te dan un cigarro, a veces agua, hasta que te recuperai. Al otro día se publica en Facebook: -perdí la dignidad, quedé pal hoyo, súper buena la fiesta”. (Entrevista staff)

Las redes sociales, específicamente Facebook configuran una parte importante de la circulación de comentarios posfiesta. La importancia del exhibirse. Constituyen el instante de la híper-exposición. Las interacciones en Facebook, específicamente escritas en el "evento" (apartado en Facebook creado especialmente para cada fiesta) tienen tres dimensiones: encontrar a personas que conocieron dentro del lugar, conocer el registro fotográfico y los comentarios de la fiesta.

\section{Casa de Salud.}

Desde que abrió, el año 2013, Casa de Salud -con 2.000 mt² $^{2}$ se ha caracterizado como concepto por mezclar la fiesta, las artes y la música. Esta propuesta va de la mano de G. Estrada, más conocido como DJ Negro Pésimo, músico de trayectoria y reconocido impulsor y difusor de la cultura urbana y la música en Concepción desde mediados de los años 90. Con el paso del tiempo 
este espacio ha logrado posicionarse y consolidarse como una alternativa con un sello particular en la ciudad de Concepción; y también fuera de ella.

Una de las características centrales del local es su versatilidad. Cuenta con diferentes ambientes que funcionan de modo autónomo, pero con una lógica relacional e interdependiente, generando la sensación de encontrar muchas fiestas simultáneas en un solo lugar. Esta característica física y de diseño de ambiente se constituye en uno de los principales motivos por el que concurren e interactúan diversos tipos de jóvenes y usuarios; integrando diversos mundos sociales, gustos y generaciones.

\section{MEZCLANDO FIESTAS.}

Es jueves, son cerca de las 21:30 hrs., desde afuera se observa lo que podría ser un galpón industrial. Hay muchos taxis y automóviles estacionados en la calle. Hay un primer control en el acceso. Luego hay una boletería y también un segundo control para cortar ticket. La entrada es cara, aunque incluye "cover". Los que están suscritos a una lista que tiene el local o su Facebook, pueden acceder gratis hasta cierta hora. Una vez adentro hay una especie de túnel laberíntico, se observan varios sofás como estaciones de conversación, espera y tránsito. También hay coloridos cuadros en los muros de acceso. Un corredor que expone cuadros diversos y pinturas, distintas manifestaciones plásticas.

Primer ambiente: el “salón principal” está compuesto por dos niveles, una barra de madera de 10 a 12 metros, mesas y sillas para compartir, un escenario donde se presentan bandas y una mesa para los DJ. Suena potente la música de una banda local en vivo. En este ambiente se observa un enjambre humano agolpado en la barra. Múltiples e incesantes circulaciones y flujos de usuarios entrando y saliendo por distintos accesos. Esta zona puede contener fácil a 100 personas en un día de “carrete” normal. La ambientación del lugar está cuidadosamente armada, llena de detalles: bicicletas viejas en la estructura sobre la barra, además de cuadros, murales y géneros temáticos que evocan un 
102 Trayectorias e inflexiones en el espacio de ocio festivo juvenil en la ciudad de Concepción - Chile

universo taoísta, hindú, balcánico, étnico, mestizo. Hay un espacio dedicado al budismo, una especie de altar que está sobre la entrada del baño de hombres y también tiene un mural en la pared trasera. Aunque se mezcla con una estética de factoría. Se circula por ramplas. Hay una plataforma en altura donde se ubica la gente que se ocupa del sonido y la iluminación. Para las tocatas de las bandas hay un proyector, pantallas y diferentes luces, lo que crea el ambiente cálido y envolvente de la fiesta. Durante la noche este espacio pasa por fases. No es estático, es flexible y móvil, está en permanente interacción y construcción. En un comienzo con música ambiente para conversar, beber, comer algo, compartir, mirarse. Luego, más cerca de las 23:00 hrs. comienza la música en vivo. Allí cambia la dinámica, tipo tocata. La última fase está definida por los DJ que generan una atmósfera cuya centralidad está definida por el baile.

Segundo ambiente: se le conoce como "salón de la fama", el cual está completamente dedicado a la escena electrónica. Funciona en simultáneo e interdependencia con el anterior. El ambiente es más minimalista. Tiene una capacidad para recibir un máximo aproximado de 50 personas. Posee una pequeña barra con una oferta de licores más sofisticada. Se observa una presencia y un gusto en los usuarios más elaborado, más producido en su estética. Hay una pequeña pista de baile. $\mathrm{Y}$ sofás que la envuelven para compartir, mirarse, residir. En un comienzo los muros estaban ambientados con fotografías de diferentes bandas de la ciudad, luego pasó a estar decorada con aves, esculturas y reproducciones visuales. Hay una mesa para el DJ. Ellos también rotan a lo largo de la noche. Además cuenta con dos proyectores en el salón, que generan imágenes líquidas y a espaldas del DJ. Acá toda la noche es baile, es una especie de pecera amniótica e hipnótica de ritmos y sonidos "beats”, house en interacción con otros géneros. La gente aquí no detiene la mirada sobre nada en particular. Observa, pero des-afectadamente.

Tercer ambiente: conocido como la "unidad de geriatría”. Cuenta con una variada oferta dependiendo del día. Hay presentación de bandas, obras de 
teatro, performance, lectura de poemas y toda una gama de opciones ligadas a la difusión del arte alternativo, emergente y que no se consume en circuitos oficiales. A ratos parece un galpón cultural. Tiene dos niveles y está cuidadosamente equipado y diseñado, con una imagen más “vintage”, dialoga con elementos antiguos como máquinas de escribir y proyectores viejos. Posee su propia barra, de aproximadamente 10 metros, con cubierta de madera rústica. Ésta suele operar como puerto o embarcadero para usuarios menos móviles. Este espacio está compuesto por un escenario, en cuyos laterales hay dispuestas butacas recicladas o recuperadas de un algún cine o teatro antiguo, dando la sensación de anfiteatro, con una capacidad para contener a unos 50 espectadores. También hay mesas y sillas de madera dispuestas frente al escenario. En el segundo piso hay un mural con rostros de mujeres y también sillas y mesas plegables. La iluminación está centrada en el escenario, donde se presentan diversas manifestaciones artísticas. Este espacio fácilmente puede acoger a unos 100 usuarios. La dinámica de este espacio está dada por la primacía de la expresión artística, por lo que puede pasar de la puesta en escena de una obra de teatro a la puesta en escena festiva con los usuarios cotidianos bailando en el escenario, y con su propia audiencia que observa el rito del baile sin efectos coreográficos.

Cuarto ambiente: conocido como "el patio”, es un espacio diseñado para fumadores variados y tiene gran relevancia para los asistentes a Casa de Salud. Como todo patio, no posee techo, y se puede observar el oscuro cielo nocturno de la ciudad. Tiene pocas mesas y sillas; y está ambientado con diversas máscaras plurinacionales que cuelgan de sus muros, todo un universo tribal y rostros que observan el patio y a quienes comparten en él. Al fondo destaca un enorme mural alegórico. Con el tiempo diseñaron lo que se denominó la “animita de los deseos"; un espacio para que los usuarios escriban sus diferentes deseos y anhelos. 
104 Trayectorias e inflexiones en el espacio de ocio festivo juvenil en la ciudad de Concepción - Chile

\section{DIVERSAS (CON)VIVENCIAS JUVENILES.}

En este universo simbólico y estético es posible extrapolar y construir una tipología preliminar de usuarios vinculados a ciertas prácticas que se generan al interior del local, donde orbitan al menos 2 grupos distintivos en torno a códigos juveniles ligados al consumo cultural: por un lado grupos de jóvenes que son considerados como “zorrones”, y que podríamos asociarlos preliminarmente con lo que también se denominan “incorporados” (Reguillo, 2000) o jóvenes convergentes; y por el otro, grupos de jóvenes que son considerados como más “under”, y que se podrían caracterizar como más “divergentes” (Reguillo, 2000; Urteaga, 2011) respecto a lo comercial (mainstream) y a las convenciones sociales que les ofrece la industria y la generación adulta, sin que por ello dejen de estar integrados en una estructura de oportunidades. Esta construcción analítica se expresa de modo dicotómico y toma forma dentro de la dinámica del local. Dicha tipología además supone empíricamente una heterogeneidad y flexibilidad en su modo de estructuración y escenificación interna.

\section{JÓVENES “ZORRONES” / CARRETE FOREVER.}

Provienen en su mayoría de estratos medios emergentes y medios altos, son jóvenes con poder adquisitivo. Muchos son estudiantes de universidades privadas y estudian carreras tradicionales (derecho, ingeniería, administración, etc.). Son usuarios más recientes del local (“aparecidos”). En el caso de los hombres, llegan en grupos y en automóvil hasta el local. Portan celulares de alta tecnología. Visten ropa estandarizada, de marcas costosas y reconocidas, sin ser sofisticados. Son más bien de estilo pragmático. Muchas veces son los primeros en adquirir nuevos productos o juguetes tecnológicos. Responden a fenotipos de masculinidad tradicional. De cuerpos entrenados y musculosos. Proyectan una actitud corporal que coloniza el espacio y se sienten "ganadores". Se caracterizan por “carretear” mucho, beber cerveza, ron y piscola. Se enfocan en 
el presente, el entretenimiento, el deporte competitivo, el ocio y el disfrute. Consumen de modo ostentoso y demostrativo. Fotografían de modo constante lo que hacen en el local. Exacerban a través de sus hábitos de consumo la proyección de su universo interior, para obtener reconocimiento de su entorno.

Las chicas suelen usar maquillaje en su rostro de modo expresivo y pronunciado. Llevan ropa costosa y de marcas reconocidas, usan carteras y marcan distinciones performativas con el uso del cuerpo en el espacio. Muchas lo refuerzan con el uso de zapatos con plataforma o tacos altos. Llevan escote visiblemente pronunciado. La ropa está ceñida al cuerpo.

Respecto de sus prácticas, gustan consumir marihuana. Tienen un gusto más inclinado hacia la música electrónica, más comercial. Usan Casa de Salud para bailar diferentes géneros musicales. El carrete de jóvenes zorrones se relaciona con pasarlo bien entre iguales, bailar, compartir con amigos y conocidos. Buscan disfrutar del lugar de moda y participar de las redes sociales vinculadas a éste. Valoran Casa de Salud porque se teje un ambiente "buena onda", relajado, donde se puede carretear tranquilo y sin riesgos. La "buena onda” también está definida aquí porque excluye el ingreso de flaites al lugar. Este grupo de jóvenes no destaca por consumir las propuestas artísticas que desarrolla en vivo el local. Aun cuando es un grupo que está abierto a experimentar situaciones nuevas.

\section{JóVENES “UNDER” / OLD IS COOL.}

Aquí identificamos de preferencia a estudiantes universitarios de carreras no tradicionales (humanidades, diseño, etc.) y jóvenes relacionados con el arte y la cultura. En general son usuarios más antiguos del local. Gustan de la música independiente, la conversación, lo que no es comercial. Visten con ropa vintage, de segunda mano, modificada. Generalmente ceñida al cuerpo. Cultivan una estética sofisticada sin parecerlo. Rechazan los códigos de la 
106 Trayectorias e inflexiones en el espacio de ocio festivo juvenil en la ciudad de Concepción - Chile

moda contingente, buscan consumir, actualizar, re combinar y escenificar estilos retro. Muchos destacan por utilizar piercings y llevar cortes de pelo no convencionales. Nada muy estridente. No beben demasiado alcohol, comparten cigarrillos y privilegian bailar en salón principal. Vibran con la música. Algunos, cuando bailan, proyectan estar aburridos y poco interesados en lo que hacen; subsumidos en una actitud "blasé".

Para estas juventudes Casa de Salud tiene valor como "epicentro" cultural de la ciudad, abierto al desarrollo de las artes escénicas, la plástica, la fotografía, el diseño, la música de bandas locales y emergentes de la ciudad. Se observan estilos juveniles más cercanos al llamado hipster. Son consumidores profusos de arte y ocio. Se distinguen por poseer un sofisticado capital cultural y también sub-alterno; manejan esos códigos que les reportan prestigio en su entorno social, sin ostentar con ello. Muchos tienen opinión política y una narrativa crítica sobre aspectos como la hetero-normatividad, el mundo adulto, la familia, la escuela y la educación; son proclives al uso de drogas y la despenalización de la marihuana, la soberanía alimentaria, etc. Hay fuerte presencia de jóvenes que participan en movimientos ciudadanos, espacios horizontales, colectivos universitarios, okupas, muchos participan de la bicicultura, etc.

De este modo, Casa de Salud funciona como un caleidoscopio de sociabilidades juveniles, re combinando estilos glocales y sensibilidades plurales en un mismo lugar. En este espacio se desarrolla un "carrete" que vincula explícitamente el arte y la fiesta, lo que propicia la co-presencia de juventudes disímiles en un mismo lugar. Algunos prefieren "residir” en el polo de lo puramente festivo, otros prefieren circular y desplazarse por situaciones variadas, armando promiscuamente y personalizadamente su propio festival de relaciones sociales, consumos, emociones y experiencias estéticas. Aquí, lograr un estilo o gusto adecuado no se reduce simplemente a una cuestión de dinero, por sobre todo se trata de una cuestión de buen gusto; lo que implica un trabajo 
simbólico importante en y con la red de consumos en la cual estos jóvenes interactúan (Urteaga, 2011), reafirmando fronteras grupales laxas y comunicando performativamente signos de distinción sin tensión, es decir, que no alcanzan a cristalizar en conflicto o disputa social.

\section{ConClusiones (MUChO MÁS QUE OCIO, FIESTA Y FASCINACión ESTÉTICA).}

En términos muy generales y preliminares, se pueden observar varias tendencias e inflexiones al interior de las prácticas y significados del ocio festivo juvenil, sobre todo en términos de proceso histórico y estructuras en formación o disolución.

Hemos puesto el énfasis en la descripción y comprensión de las sociabilidades festivas juveniles, de preferencia en el heterogéneo y fragmentario mundo asociado a los grupos medios, teniendo en consideración que en el contexto chileno actual predominan: desiguales modos de ser joven; creciente incertidumbre en sus trayectorias de vida; y la desestabilización de instituciones como la familia, la escuela, el trabajo, la política, etc. En este escenario complejo muchos jóvenes orientan la búsqueda de sentidos de forma muy distinta a la generación de sus padres. Dichas búsquedas aparecen de modo más perceptible en la construcción de su mundo simbólico, en sus consumos culturales y en los espacios intersticiales y de ocio festivo en los que participan (Wortman, 2003; Nateras, 2010; Urteaga, 2011).

En cuanto a las rupturas y persistencias más visibles, y en absoluto generalizables a otros casos de estudio, destacamos:

i) Un primer signo de inflexión consistente está configurado por la privatización del carrete y el ocio festivo juvenil nocturno. Pues, si bien desde mediados de los años 50 y hasta bien entrados los años 90 era posible percibir una coexistencia entre formas más comunitarias y autogestionadas de ocio 
108 Trayectorias e inflexiones en el espacio de ocio festivo juvenil en la ciudad de Concepción - Chile

festivo, junto con formas más masivas y comerciales, sin verificarse la hegemonía de una formula sobre otra; en la actualidad, particularmente desde comienzos del siglo XXI, se observa un fuerte predominio de las lógicas comerciales y una diversificación de la industria del ocio global por sobre las tendencias más espontáneas y de auto-afirmación comunitaria. De modo que, si en los 90 el carrete constituyó una forma subterránea de reagrupamiento juvenil en espacios como la calle, la plaza, el parque, el bar, etc., hoy los vínculos aparecen expuestos a un proceso de aceleración y fugacidad que no alcanzan a coagular en comunidades de referencia más estables, sino en una proliferación incesante de diversidades sin anclajes o puertos que las comuniquen.

Lo anterior como un efecto estructural de los procesos de modernización y penetración de las lógicas de segmentación mercantil en el ámbito del ocio festivo, que contribuyen a acentuar los modos fragmentarios y desiguales de ser joven en Chile. Esto se vincula con la fuerte tendencia a la neoliberalización del espacio y la privatización de la noche en nuestro país (Nofre, 2013). Corriente “expulsiva” que muchas veces obliga a reagrupar el carrete en los ámbitos domésticos, directamente en calles y plazas, o bien, impulsa a innovar y a generar circuitos menos masivos e industrializados de ocio festivo.

Aspectos que se expresan en la tendencia nacional que repliega el espacio de ocio festivo juvenil al ámbito de la residencia particular, donde el espacio preferido por la juventud para compartir con las amistades se encuentra actualmente en los domicilios particulares (75\%); en segundo lugar, espacios como la calle y la plazas (41\%); más atrás se mencionan espacios como los pub o las discotecas con un 27\% de las opciones (INJUV, 2010).

ii) En otro estrato de rupturas complementarias con la anterior, se verifica una disminución progresiva de la percepción de riesgo en torno al consumo de marihuana. Su presencia, acceso y variedad es trasversal a todos los tipos de carrete y estratos sociales. Se observa una presencia muy limitada de otras sustancias, como la cocaína y sus derivados. Al mismo tiempo 
identificamos la expresión abierta y desprejuiciada de sexualidades móviles, particularmente en los grupos de jóvenes que participan de espacios como las Party Hard o similares, marcando una ruptura con los espacios festivos de otras generaciones, particularmente la de los años 80 y anteriores a ese momento. Existe un respeto progresivo y tolerancia generacional por la afectividad y la sexualidad que cada uno desea expresar, aun cuando no podemos desconocer la persistencia de estereotipos tradicionales de género $\mathrm{y}$ patrones de comportamiento sexista en las actuales generaciones que se evidencian y escenifican en los espacios de ocio festivo. Por su parte, las redes sociales y las NTIC constituyen otro componente de esta ruptura con las formas de organización del ocio festivo impulsadas por otras generaciones. Estas tecnologías contribuyen a viralizar la experiencia social festiva, pero también a construir nuevos lazos sociales, vínculos frágiles y móviles, más independientes, menos anclados al peso de las tradiciones y los lugares, más próximos a las comunidades emocionales globales, con sentidos fugaces y centrados en un presente ubicuo (Ganter, 2015). Aunque sin desdibujar la estructura de los desiguales modos de ser joven.

iii) Sobre jóvenes que producen y crean espacios festivos para jóvenes. Si bien esta tendencia se observa en otros momentos históricos, en la actualidad se evidencia una emergencia y proliferación de estos circuitos más independientes en las grandes ciudades, constituyendo una contra tendencia a lo que aquí llamamos la privatización y segmentación más estructural del carrete. Estos circuitos se caracterizan por un nivel de producción material y simbólica de alta elaboración y de autonomía relativa respecto de las lógicas estrictamente mercantiles y masivas. Aquí se re combinan promiscuamente elementos de la cultura global con la local, tipos de fiestas, usuarios, estilos y ambientes culturales. Conformando circuitos de innovación social, particularmente para el caso de Casa de Salud, donde el consumo de espacios de ocio festivo nocturno se mezcla con la producción de “espectáculos” en vivo: música, literatura, artes escénicas, plástica, etc. Se trata de un conjunto de productores culturales 
110 Trayectorias e inflexiones en el espacio de ocio festivo juvenil en la ciudad de Concepción - Chile

jóvenes o de signo juvenil (pertenecientes a distintas generaciones y nuevos grupos medios) que auto-gestionan recursos y generan colectivamente un espacio público y de difusión de la cultura urbana: un espacio de encuentro entre diversas juventudes y estilos; un espacio de intercambio interclasista, donde se evoca la disolución de los hábitos de clase (para el caso de las Party Hard); un espacio de encuentro intergeneracional y de fusión-difusión del arte glocal y la expresividad festiva juvenil (para el caso de Casa de Salud). Todo un activo "trabajo simbólico" (Willis, 1999) que muchos jóvenes realizan tácticamente- sobre una red compleja de consumos (música, relaciones, ropa, accesorios, tecnología, estilos, lugares, etc.) a modo de compensar la actual precariedad de sentidos y promesas que la escuela o el trabajo convencional no le ofrecen.

iv) Otra tendencia interesante es que, si bien muchas de las interacciones de consumo en estos espacios de ocio festivo se han organizado ("históricamente") a partir de la búsqueda de prestigio y distinción social frente a otros grupos, haciendo ostentación de ciertos signos tangibles de éxito social (la marca), en la actualidad es posible percibir una aceleración de formas de consumo orientadas por el deseo incesante de vivir nuevas experiencias sociales y emocionales al interior de espacios de ocio festivo; eclipsando momentáneamente el vector de las pertenencias de clase. Más que ofrecer servicios se ofrecen vivencias personalizadas. Hay un consumo para la autorealización lúdica que comienza a tomar fuerza en estos espacios sociales frente a las tradicionales prácticas de consumo demostrativo y centrado en un otro social. Esta tendencia emergente se puede observar de modo particular en los usuarios de las Party Hard como en los llamados grupos más divergentes que participan en Casa de Salud.

v) En interdependencia con el punto anterior, se observa para ambos casos de estudio, una tendencia marcada por la disolución de la presencia antagónica de los llamados estilos subculturales (Hebdige, 2004) con un fuerte 
componente de clase, y las expresiones conceptualizadas como "tribus urbanas" que predominaron fuertemente durante la década de los 90 y los inicios del siglo XXI en Chile. Lo anterior como efecto de un agotamiento interno y una sobreexposición en la industria del espectáculo de dichas expresiones (Hall \& Jefferson, 2014), pero sobre todo porque -estructuralmente- en el Chile actual se encuentran cada vez más fragmentadas las comunidades humanas y los vínculos colectivos, con aceleraciones en las dinámicas de subjetivación multiforme y con escasos horizontes de convergencia (PNUD, 2012). Procesos que ameritan nuevas lecturas de campo que permitan generar nuevas categorías para las dinámicas y las subjetividades que aquí intentamos comprender.

vi) Como continuum en la historia que aquí hemos reconstruido brevemente, los múltiples escenarios de carrete y la construcción de los mundos simbólicos asociados con este, constituyen -más que una fascinación estéticauna poderosa mediación social (entre lo hegemónico y lo subalterno), una zona de innovación intersubjetiva donde se juegan aspectos que no se reducen únicamente a la diversión, sino una zona donde se constituye el aprendizaje de los códigos básicos de la socialidad juvenil entre pares generacionales (Mead, 2006; Urteaga, 2011), esto es, donde se aprehende el lenguaje de la corporalidad, los códigos de la sexualidad y la afectividad; la gestión de riesgos y el uso de sustancias; la gestión de los límites; el cómo, cuándo, dónde, con quiénes y qué se debe consumir o no consumir; el goce y la autonomía personal; la confianza en sí mismo y en los otros; el conocer gente nueva, la amistad y la lealtad, la cooperación entre pares y entre generaciones diferentes. Toda una urdimbre de signos y prácticas culturales -propias de estos gruposque se internalizan en vivo y entre pares, pues carentes de espacios donde ejercer la autonomía más allá del tutelaje asimétrico y restringido del hogar parental, la escuela o el trabajo, se re apropian de un espacio de uso público como la discoteca, el pub, la calle- para recrear su experiencia social, temporal e interpersonal, y construir un territorio que les otorgue refugio provisorio para la producción de nuevos sentidos compartidos, generando recorridos, 
112 Trayectorias e inflexiones en el espacio de ocio festivo juvenil en la ciudad de Concepción - Chile

estaciones, circuitos y ocupaciones que van reorganizando el complejo y jerarquizado espacio urbano.

\section{REFERENCIAS}

American Anthropological Association (AAA) (1998). Code of ethics of the American Anthropological Association. http://www.aaanet.org/committees/ethics/ethcode.htm Consultado: [01/11/2014].

Benítez, L., González, Y. \& Senn, D. (2016). Punkis y New Waves en dictadura: rearticulación y resistencia de las culturas juveniles en Chile (1979-1984). Revista Latinoamericana de Ciencias Sociales, Niñez y Juventud, 14 (1), pp. 191-203.

Bonvillani, Andrea (2013). Cuerpos en marcha. Emocionalidad política en las formas festivas de protesta juvenil. Revista Nómadas, número 39, pp. 91 - 103. Bogotá.

Contreras, Daniel (1996). Sujeto juvenil y espacios rituales de identidad: comentarios sobre el caso del carrete. Última Década $\mathrm{N}^{\mathrm{o}}$ 5, pp. 161196. Viña del Mar: CIDPA.

Escárate, Tito (1994). Frutos del país. Historias del rock chileno. Santiago de Chile: FONDART.

Feixa, Carles (1989). Pijos, progres y punks. Hacia una antropología de la juventud urbana. En Revista de Juventud, $N^{\circ}$ 34, pp. 3-15. Madrid: Instituto de la Juventud.

Feixa, Carles (1998). De jóvenes, bandas y tribus. Barcelona: Ariel.

Fernández, Francisca (2011). La movida alternativa en Chile. Recuperado de: http://centex.portalpatrimonio.cl/wpcontent/uploads/2011/09/Fiestasalternativas-en-Chile.pdf

Ganter, Rodrigo y Zarzuri, Raúl (1999). Tribus urbanas: por el devenir cultural de nuevas sociabilidades juveniles. Revista de Trabajo Social Perspectivas $\mathrm{N}^{\circ}$ 8. Santiago de Chile: Universidad C. Silva Henríquez.

Ganter, Rodrigo (2015). Consumo cultural juvenil: apuntes y pistas para posibles líneas de investigación en el Chile actual. En Cottet, Pablo. Juventudes: metáforas del Chile contemporáneo. Santiago de Chile: Ed. Ril.

González, Yanko (2011). Primeras culturas juveniles en Chile: Pánico, malones, pololeo y matiné. Revista Atenea, (503), pp. 11-38. Concepción, Chile. 
Guber, Rosana (2001). La etnografía, método, campo y reflexividad. Grupo Editorial Norma, Bogotá.

Hall, Stuart. \& Jefferson, T. (2014). Rituales de resistencia. Subculturas juveniles en la Gran Bretaña de postguerra. Madrid: Traficantes de Sueño.

Hebdige, Dick (2004). Subcultura: el significado del estilo. Buenos Aires: Paidós.

Instituto Nacional de la Juventud, INJUV (2009). Sexta Encuesta Nacional de Juventud. Santiago: Gobierno de Chile.

Jara, Loreto. (2003). Del malón al carrete. Las transformaciones del divertimiento en Santiago 1960 - 1990. Una aproximación histórica desde la oralidad. Universidad de Santiago. Santiago, Chile.

Leff, Laura; Leivi, Milena \& García, Alejandra (2003). Raves: las fiestas del fin del milenio. En Wortman, Ana (2003). Pensar las clases medias. Consumos culturales y estilos de vida urbanos en la Argentina de los noventa. Buenos Aires: La Crujía.

Margulis, Mario (1994). La Cultura de la Noche. La vida nocturna de los jóvenes en Buenos Aires. Buenos Aires: Biblos Sociedad.

Matus, Ch. (2000). Tribus urbanas: entre ritos y consumos. El caso de la discoteque Blondie. Última Década, N 13, pp. 97-120. Viña del Mar: CIDPA.

Matus, Ch. (2005). El carrete como escenario: Una aproximación etnográfica a la sexualidad juvenil en espacios y contextos ocasionales en Polis [En línea], $\mathrm{N}^{\mathrm{o}}$ 11, Puesto en línea el 27 agosto 2012, consultado el 17 agosto 2014.

Martínez, Roger (2003). Espacios musicales. La música pop(ular) y la producción cultural del espacio juvenil. Revista Jóvenes; revista de estudios sobre juventud, año 7, N¹9, pp. 152-183. México: IMJ.

Mead, Margaret (2006). Cultura y compromiso: estudio sobre la ruptura generacional. Barcelona: Gedisa.

Melcer, Teresa (2003). Y todo a media luz...misteriosa Buenos Aires. Los sinuosos caminos del arte. En Wortman, Ana (2003). Pensar las clases medias. Consumos culturales y estilos de vida urbanos en la Argentina de los noventa. Buenos Aires: La Crujía.

Muñoz, Víctor (2002). Movimiento social juvenil y eje cultural, dos contextos de reconstrucción organizativa (1976-1982 / 1989-2002). Última Década, N 17. Santiago de Chile: CIDPA. 
114 Trayectorias e inflexiones en el espacio de ocio festivo juvenil en la ciudad de Concepción - Chile

Nateras, Alfredo (2010). Adscripciones identitarias juveniles: tiempo y espacio social. El Cotidiano, № 163, pp. 17-23. México: Universidad Autónoma Metropolitana Azcapotzalco.

Nofre, J. \& Martin, J. (2009). Ocio nocturno, gentrificación y distinción social en el centro histórico de Sarajevo. Anales de Geografía, № 29. Madrid: Universidad Complutense de Madrid.

Nofre, Jordi (2013). De lo sórdido a lo vintage, de la marginalización a la distinción. Gentrificación y ocio nocturno en Cais do Sodré, Lisboa. Forum Sociológico, № 23.

Palma, Daniel (2013). Hijos de la trampa. Santiago de Chile: Asterión Ediciones.

Pallarés, Joan \& Feixa, Carles (2000). Espacios e itinerarios para el ocio juvenil nocturno. Revista de Estudios de Juventud, N 50. Madrid: INJUVE.

Pincheira, Rodrigo (2017). Rock, memoria y juventud. El festival hippie en Quillón. Ponencia presentada en la Escuela de Verano UdeC, Espacios, expresiones y manifestaciones de sociabilidad política y cultural en el Gran Concepción durante la dictadura cívico-militar 1973-1988. Concepción, Chile.

PNUD (2012). Informe de desarrollo humano en Chile. Bienestar subjetivo: el desafío de repensar el desarrollo. Santiago: PNUD.

Ramírez, Alejandra (2012). ¡Hoy es noche de antro! La discoteca como espacio productor de diferenciación social entre los jóvenes de Cuernavaca. Gazeta de Antropología, No 28 /1. México: Morelos.

Reguillo, Rossana, (2000). Emergencia de culturas juveniles. Estrategias del desencanto. Buenos Aires: Grupo Editorial Norma.

Santis, José (2009). Lugares de la vida nocturna en Santiago de Chile 1973 1990. Revista Electrónica DU\&P, volumen V, $\mathrm{N}^{\circ} 16$. Santiago de Chile: Universidad Central.

Salazar, Gabriel, (2002). Historia Contemporánea de Chile Tomo V: Niñez y Juventud. Santiago, Chile: LOM.

Sagredo, Juan Francisco (2013). Identidad y proscripción: Espacios musicales como formas de resistencia cultural al interior de la Universidad de Concepción, 1973-1983. Tesis de Magister en Historia de Occidente. Universidad del Biobío: Concepción, Chile.

Thornton, Sarah (1996). Club Cultures. Music, media and subcultural capital. New England, Cambridge: Cambridge, Wesleyan University Press.

Urteaga, Maritza (2011). La construcción juvenil de la realidad. Jóvenes mexicanos contemporáneos. Iztapalapa, México: Universidad Autónoma Metropolitana. 
Urteaga, Maritza y Ortega, Enedina (2004). Identidades en disputa: fresas, wannabes, alternos, pandros y nacos. En Rossana Reguillo (coord.). Tiempos de híbridos, entre siglos jóvenes México-Cataluña, pp. 114-132. México: Instituto Mexicano de la Juventud.

Valenzuela, José Manuel (2009). El futuro ya fue. Socioantropología de los jóvenes en la modernidad. México: El Colegio de la Frontera Norte/Casa Juan Pablos.

Willis, Paul (1999). Producción Cultural y Teorías de la Reproducción. Fernández, Enguita. Sociología de la Educación. España: Ariel.

Wortman, Ana (2003). Pensar las clases medias. Consumos culturales y estilos de vida urbanos en la Argentina de los noventa; Buenos Aires: La Crujía.

Zarzuri, R. \& Ganter, R. (2002). Culturas juveniles, narrativas minoritarias y estéticas del descontento. Santiago de Chile: Universidad C. Silva Henríquez.

\section{GLOSARIO DE TÉRMINOS}

- Borrarse: quedar inconsciente por consumo de alcohol

- Comerse: Encuentro amoroso que no implica tener relaciones sexuales

- Curarse: Consumir alcohol en exceso. Al igual que el "volarse" del consumo de cannabis, se utiliza para definir el estado de ebriedad como "estar curada/o"

- Flaite: Adscripción estética asociada con sectores de clase baja y mediabaja, de preferencia masculina. Define más una actitud asociada con las peleas y el hurto por descuido, que una pertenencia ligada a un estilo cultural más consistente.

- Pelarse: Encuentro amoroso que no implica tener relaciones sexuales.

- Previa: Antesala del carrete relacionada con el consumo de diversas sustancias como alcohol o marihuana, puede darse tanto en lugares públicos como en casas.

- Swag: corriente asociada con una forma de caminar y hablar particular; es una noción que forma parte del léxico rapero y se masifica para hombres y mujeres por el uso que cantantes como Bieber. Se asocia con nuevos grupos medios “aspiracionales”.

- Zorrito / Zorrón: adscripción performativa juvenil asociada con una nueva facción de la clase media-alta, de preferencia masculina, definida por una 
116 Trayectorias e inflexiones en el espacio de ocio festivo juvenil en la ciudad de Concepción - Chile

estética más funcional y pragmática. Por definición son considerados como "carreteros" y poseen prácticas de consumo más estridentes y demostrativas.

Recepción de artículo: noviembre 2016

Aceptación de artículo: marzo 2017 